\title{
An efficient, three-component synthesis of isoindolin-1-one-3- phosphonates under mild and solvent-free conditions
}

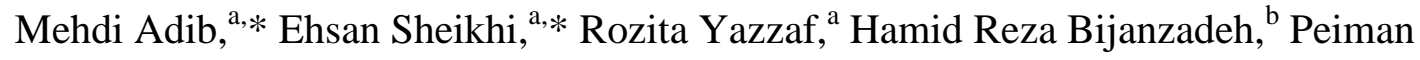 \\ Mirzaei $^{\mathrm{c}}$ \\ ${ }^{a}$ School of Chemistry, College of Science, University of Tehran, PO Box 14155-6455, \\ Tehran, Iran \\ ${ }^{\mathrm{b}}$ Department of Chemistry, Tarbiat Modarres University, Tehran, Iran \\ ${ }^{c}$ Department of Chemistry, Shahid Beheshti University, Tehran, Iran
}

\begin{abstract}
An efficient and mild three-component synthesis of isoindolin-1-one-3phosphonates is described. The reaction between a 2-formylbenzoic acid, a primary amine and a trialkyl phosphite proceeded at ambient temperature under catalyst- and solvent-free conditions to afford the desired compounds in excellent yields.
\end{abstract}

Keywords: multi-component reactions, isoindolin-1-one-3-phosphonates, 2formylbenzoic acids, primary amines, trialkyl phosphites, solvent-free synthesis.

*Corresponding author. Tel./fax: +98(21)66495291; E-mail: madib@khayam.ut.ac.ir

Recently, isoindolin-1-ones have attracted great attention as common structural motifs in naturally occurring compounds such as magallanesine, ${ }^{1}$ lennoxamine, ${ }^{2}$ and stachybotrin $\mathrm{C}^{3}$ as well as in pharmacologically important synthetic compounds such as Pagoclone (Figure 1). ${ }^{4}$ Compounds having the isoindolin-1-one scaffold have been shown to possess a broad range of biological activities including antimicrobial, ${ }^{5}$ antiviral, ${ }^{6}$ HIV-1 inhibition, ${ }^{7}$ sedative and hypnotic. ${ }^{8}$ Some isoindolin-1-ones have been claimed to assist in treating diabetes, ${ }^{9}$ obesity and hyperlipidemia, ${ }^{10}$ cancer $^{11}$ and CNS diseases. ${ }^{12}$ Also, several isoindoline derivatives have been proposed as dipeptidyl peptidase DPP8/9 inhibitors in immunohistochemical studies. ${ }^{13}$ Isoindolin-1-ones have also been used in the Diels-Alder reaction and as building blocks in asymmetric synthesis. ${ }^{14-16}$ 


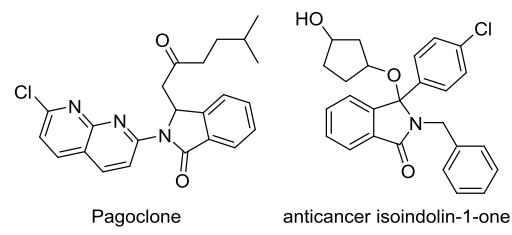

Figure 1. Examples of pharmacologically important compounds having the isoindolin-1-one core structure.

Due to the widespread biological activities of isoindoline derivatives, a variety of synthetic approaches have been reported for the preparation of these heterocycles. ${ }^{17-22}$ To date, a few synthetic routes have been reported for the preparation of dialkyl 3oxo-2,3-dihydro- $1 H$-isoindol-1-yl)phosphonates. Kolodiazhnyi and co-workers have reported a three-step sequence including reduction of phthalimides to 3hydroxyisoindolin-1-ones followed by treatment with trifluoroacetic anhydride and then triethyl phosphite to afford the corresponding phosphonates in moderate yields. ${ }^{23}$ Ordóñez and co-workers reported the synthesis of chiral isoindolin-1-one-3phosphonates via the Kabachnik-Fields three-component reaction of 2-formylbenzoic acid, an amine and dimethyl phosphite. The reactions were carried out in toluene at reflux ${ }^{24}$ under microwave irradiation ${ }^{24}$ or at $80{ }^{\circ} \mathrm{C}$ under solvent- and catalyst-free conditions $^{25}$ to give the phosphonates in low to excellent yield. Very recently, Bunce and co-workers have reported a modified Kabachnik-Fields condensation of 2formylbenzoic acid with an amine and triethyl phosphite using OSU-6, a MCM-41 type mesoporous hexagonal silica, as the catalyst. ${ }^{26}$

Although the above mentioned syntheses have proved to be suitable routes to obtain dialkyl 3-oxo-2,3-dihydro-1H-isoindol-1-yl)phosphonates, these suffer from some drawbacks such as multistep reactions, high reaction temperatures, use of catalysts and solvents and in some cases fairly low product yields.

In connection with an ongoing research program concerned with the synthesis of biologically active heterocyclic compounds, ${ }^{27}$ herein, we report an efficient and convenient method for the preparation of $N$-substituted isoindolin-1-one-3phosphonates. Thus, a mixture of a 2 -formylbenzoic acid $\mathbf{1}$, a primary amine $\mathbf{2}$ and a trialkyl phosphite $\mathbf{3}$ was stirred at ambient temperature under solvent-free conditions. ${ }^{28}$ The reactions proceeded to completion within $40 \mathrm{~min}$ to afford the corresponding isoindolin-1-one-3-phosphonates 4 in 89-98\% yields (Scheme 1 and 
Table 1). ${ }^{1} \mathrm{H}$ NMR analysis of the reaction mixtures clearly indicated formation of compounds $\mathbf{4}$ without the formation of by-products. ${ }^{29}$

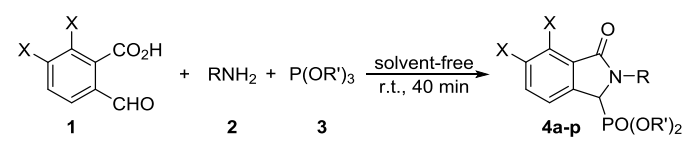

Scheme 1. Synthesis of $N$-substituted isoindolin-1-one-3-phosphonates 4.

Table 1. Synthesis of isoindolin-1-one-3-phosphonates $\mathbf{4 a -}-$. $^{\text {a }}$

\begin{tabular}{|c|c|c|c|c|c|c|c|c|c|c|c|}
\hline $\mathrm{X}$ & Amine 2 & $\mathrm{R}^{\prime}$ & Product & & $\begin{array}{l}\text { Yield } \\
(\%)^{b}\end{array}$ & $X$ & Amine 2 & $\mathrm{R}^{\prime}$ & Product & & $\begin{array}{l}\text { Yield } \\
(\%)^{\text {b }}\end{array}$ \\
\hline $\mathrm{H}$ & & $\mathrm{Me}$ & & $4 a$ & 98 & $\mathrm{OMe}$ & & $\mathrm{Me}$ & & $4 i$ & 93 \\
\hline $\mathrm{H}$ & & $\mathrm{Et}$ & & $\mathbf{4 b}^{23,26}$ & 96 & $\mathrm{H}$ & $\mathrm{IH}_{2}$ & $\mathrm{Me}$ & & $4 j$ & 95 \\
\hline $\mathrm{OMe}$ & & $\mathrm{Me}$ & & $4 c$ & 93 & $\mathrm{H}$ & $\mathrm{NH}_{2}$ & $\mathrm{Et}$ & & $4 k^{26}$ & 98 \\
\hline $\mathrm{OMe}$ & & $\mathrm{Et}$ & & 4d & 92 & $\mathrm{H}$ & & $\mathrm{Me}$ & & $41^{24}$ & 93 \\
\hline $\mathrm{H}$ & & $\mathrm{Me}$ & & $4 e$ & 97 & $\mathrm{H}$ & & $\mathrm{Et}$ & & $4 m^{26}$ & 93 \\
\hline $\mathrm{H}$ & & $\mathrm{Et}$ & & $4 f$ & 97 & OMe & & Et & & $4 n$ & 92 \\
\hline $\mathrm{H}$ & & $\mathrm{Me}$ & & $4 g$ & 94 & $\mathrm{H}$ & & $\mathrm{Me}$ & & $\mathbf{4 o}^{25}$ & $89^{c}$ \\
\hline $\mathrm{H}$ & & $\mathrm{Et}$ & & $\mathbf{4 h}^{26}$ & 95 & $\mathrm{H}$ & & $\mathrm{Me}$ & & $4 p^{25}$ & $90^{\mathrm{d}}$ \\
\hline
\end{tabular}

\footnotetext{
${ }^{a}$ Reaction conditions: 2-formylbenzoic acid $(\mathbf{1}, 1 \mathrm{mmol})$, amine $(\mathbf{2}, 1 \mathrm{mmol})$, trialkyl phosphite $(\mathbf{3}, 1.1 \mathrm{mmol})$; solventfree, ambient temperature, $40 \mathrm{~min}$.

${ }^{\mathrm{b}}$ Isolated yield.

${ }^{\mathrm{c}}$ Diastereoisomeric ratio: $>97: 3$ (determined from the ${ }^{31} \mathrm{P}$ NMR of the crude product); $(3 S, 1$ ' $R$ )-diastereoisomer was the major product. $^{25}$

${ }^{\mathrm{d}}$ Diastereoisomeric ratio: >97:3 (determined from the ${ }^{31} \mathrm{P}$ NMR of the crude product); $(3 R, 1$ 'S)-diastereoisomer was the

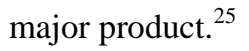

The structures of the isolated products were deduced by IR, ${ }^{1} \mathrm{H},{ }^{13} \mathrm{C}$ and ${ }^{31} \mathrm{P}$ NMR spectroscopy, mass spectrometry and elemental analyses. The IR spectrum of $4 \mathbf{e}$ showed a stretching band for the $\mathrm{C}=\mathrm{O}$ bond of the amide group at $1693 \mathrm{~cm}^{-1}$. The 
mass spectrum of $4 \mathbf{e}$ displayed the molecular ion $\left(\mathrm{M}^{+}\right)$peaks at $\mathrm{m} / z 367\left({ }^{37} \mathrm{Cl}\right)$ and 365 $\left({ }^{35} \mathrm{Cl}\right)$ which were consistent with the 1:1:1 adduct of 2-formylbenzoic acid, 2chlorobenzylamine, and trimethyl phosphite, with the loss of $\mathrm{H}_{2} \mathrm{O}$ and $\mathrm{MeOH}$. In the ${ }^{1} \mathrm{H}$ NMR spectrum of $\mathbf{4 e}$, two doublets were observed at $\delta=3.37$ and $3.58 \mathrm{ppm} ;{ }^{3} J_{\mathrm{PH}}$ $=10.7,10.9 \mathrm{~Hz}$, respectively for the diastereotopic $\mathrm{POCH}_{3}$ groups. A distinguishing doublet was observed at $4.69(J=13.1 \mathrm{~Hz})$ for the methine moiety of the five membered ring due to a geminal coupling with the phosphonate P-atom. Two doublets were apparent for the diastereotopic $\mathrm{H}$ atoms of the benzyl residue (4.77 and $5.27,{ }^{2} J=15.9 \mathrm{~Hz}$ ) as well as characteristic multiplets with the appropriate chemical shifts and coupling constants for the eight aromatic $\mathrm{H}$-atoms in the range of 7.05-7.74. The ${ }^{1} \mathrm{H}$ decoupled ${ }^{13} \mathrm{C}$ NMR spectrum of $4 \mathbf{e}$ showed characteristic signals at $43.3\left(\mathrm{NCH}_{2}\right)$, two doublets at 53.6 and $53.9\left({ }^{2} J_{\mathrm{PC}}=7.2,7.0 \mathrm{~Hz}\right.$, respectively), arising from the diastereotopic $\mathrm{POCH}_{3}$ groups. A characteristic resonance was observed at 56.6 (doublet, ${ }^{1} J_{\mathrm{PC}}=155.2 \mathrm{~Hz}$ ) due to the $\mathrm{P}-\mathrm{CH}$ moiety as well as a deshielded signal at 168.9 for the amide carbonyl group. The resonances of three Pcoupled carbons along with 9 other distinct resonances $(7 \times \mathrm{CH}$ and $2 \times \mathrm{C})$ were also observed in the range of 124.1-138.4. The ${ }^{1} \mathrm{H}$ decoupled ${ }^{31} \mathrm{P}$ NMR spectrum of $4 \mathbf{e}$ showed a signal at $\delta=20.00$ due to the phosphonate group which was in agreement with the proposed structure. ${ }^{29}$

A plausible reaction mechanism is provided in Scheme 2. It is conceivable that imine intermediate 5 formed from the condensation reaction between 2-formylbenzoic acid $\mathbf{1}$ and amine $\mathbf{2}$ may undergo nucleophilic attack of phosphite $\mathbf{3}$, generating the trialkoxyphosphonium carboxylate intermediate 6. This nucleophilic attack is facilitated by protonation of the imine with the adjacent carboxylic acid. The phosphonium group may undergo intramolecular nucleophilic attack of the adjacent carboxylate anion to form ester intermediate $\mathbf{7}$, followed by cyclization proceeding through intramolecular nucleophilic attack of the amine moiety onto the adjacent carboxylate ester to afford $N$-substituted isoindolin-1-one-3-phosphonates 4.

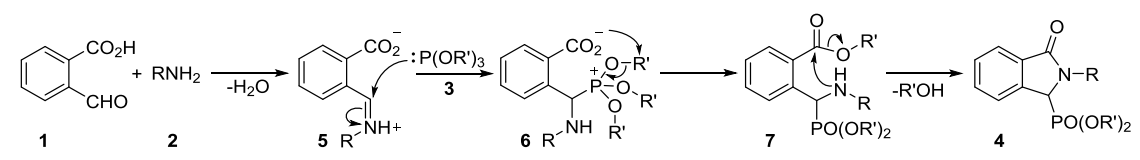


Scheme 2. Proposed mechanism for the formation of isoindolin-1-one-3phosphonates 4 .

In conclusion, we have developed an efficient three-component synthesis of isoindolin-1-one-3-phosphonates which are of potential synthetic and pharmacological interest. The reaction proceeds quickly and with no undesirable side reactions observed. Use of simple starting materials, a simple procedure and easy work-up without any need for chromatographic purification process, short reaction times and excellent yields are the main advantages of this method.

\section{Acknowledgement}

This research was supported by the Research Council of the University of Tehran.

\section{References and notes:}

1. Pace, V.; Martínez, F.; Nova, C. I.; Fernández, M.; Sinisterra, J. V.; Alcántara, A. R. Tetrahedron Lett. 2009, 50, 3050-3053.

2. Lamblin, M.; Couture, A.; Deniau, E.; Grandclaudon, P. Tetrahedron: Asymmetry 2008, 19, 111-123.

3. Nozawa, Y.; Ito, M.; Sugawara, K.; Hanada, K.; Mizoue, K. J. Antibiot. 1997, 50, 641-645.

4. Sorbera, L. A.; Leeson, P. A.; Silvestre, J.; Castaner, J. Drugs Future 2001, 26, 651.

5. Breytenbach, J. C.; Dyk, S. v; Heever, I. v. d.; Allin, S. M.; Hodkinson, C. C.; Northfield, C. J.; Page, M. I. Bioorg. Med. Chem. Lett. 2000, 10, 1629-1631.

6. Maugeri, C.; Alisi, M. A.; Apicella, C.; Cellai, L.; Dragone, P.; Fioravanzo, E.; Florio, S.; Furlotti, G.; Mangano, G.; Ombrato, R.; Luisi, R.; Pompei, R.; Rincicotti, V.; Russo, V.; Vitiello, M.; Cazzolla, N. C. Bioorg. Med. Chem. 2008, $16,3091-3107$.

7. Zhao, X. Z.; Maddali, K.; Marchand, C.; Pommier, Y.; Burke, T. R., Jr. Bioorg. Med. Chem. 2009, 17, 5318-5324.

8. Shirasaka, T.; Kunitake, T.; Tsuneyoshia, I. Brain Res. 2009, 1300, 105-113.

9. Guertin, K. R. US Patent 6482951 (B2), 2002.

10. Arakawa, K.; Nishimura, T.; Sugimoto, Y.; Takahashi, H.; Shimamura, T. US Patent 8,362,052 (B2), 2013. 
11. (a) Frank, A. J.; Man, H. W.; Ge, C.; Saindane, M. US Patent 8,415,485 (B2), 2013; (b) Willems, H. M. G.; Kallblad, P.; Hardcastle, I. R.; Griffin, R. J.; Golding, B. T.; Lunec, J.; Noble, M. E. M.; Newell, D. R.; Calvert, A. H. US Patent 8,258,175 (B2), 2012; (c) Dally, R. D.; Woods, T. A. US Patent 2014/0275121 (A1), 2014.

12. (a) Zhao, P. L.; Ma, W. F.; Duan, A. N.; Zou, M.; Yan, Y. C.; You, W. W.; Wu, S. G. Eur. J. Med. Chem. 2012, 54, 813-822; (b) Ignasik, M.; Bajda, M.; Guzior, N.; Prinz, M.; Holzgrabe, U.; Malawska, B. Arch. Pharm. Chem. Life Sci. 2012, 345, 509-516; (c) Lindsley, C. W.; Conn, P. J.; Wood, M. R.; Hopkins, C. R.; Melancon, B. J.; Poslusney, M. S.; Engers, D. W. US Patent 2014/0288084 (A1), 2014; (d) Meltzer, H. Y.; Horiguchi, M. US Patent 8,735,397 (B2), 2014.

13. (a) Dubois, V.; Van Ginneken, C.; De Cock, H.; Lambeir, A. M.; Van der Veken, P.; Augustyns, K.; Chen, X.; Scharpé, S.; De Meester, I. J. Histochem. Cytochem. 2009, 57, 531-541; (b) Jiaang, W. T.; Chen, Y. S.; Hsu, T.; Wu, S. H.; Chien, C. H.; Chang, C. N.; Chang, C. N.; Lee, S. J.; Chen, X. Bioorg. Med. Chem. Lett. 2005, 15, 687-691.

14. Stevenson, P.; McAlonan, H.; Murphy, J. P.; Nieuwenhuyzen, M.; Reynolds, K.; Sarma, P. K. S.; Thompson, N. J. Chem. Soc. Perkin Trans. 1 2002, 69-79.

15. (a) Miyabe, H.; Yoshida, K.; Kobayashi, Y.; Matsumura, A.; Takemoto, Y. Synlett 2003, 1031-1033; (b) Stajer, G.; Csende, F. Curr. Org. Chem. 2005, 9, 12771286; (c) Buchert, M.; Meinke, S.; Prenzel, A.; Deppermann, N.; Maison, W. Org. Lett. 2006, 8, 5553-5556.

16. (a) Donohoe, T. J. Sci. Synth. 2001, 10, 653-692; (b) Bonnett, R.; North, S. A. Adv. Heterocycl. Chem. 1981, 29, 341-399.

17. (a) Sundberg, R. J. In Comprehensive Heterocyclic Chemistry II, Vol. 2; Katritzky, A. R.; Rees, C. W.; Scriven, E. F. V., Eds.; Pergamon Press: London, 1996, Chapt. 3, pp 120-206; and references therein; (b) Bergman, J.; Janosik, T. In Comprehensive Heterocyclic Chemistry III, Vol 3; Katritzky, A. R.; Ramsden, C. A.; Scriven, E. F. V.; Taylor, R. J. K., Eds.; Elsevier Science: Oxford, 2008, Chapt. 3, pp 269-336; and references therein.

18. (a) Fustero, S.; Herrera, L.; Lazaro, R.; Rodriguez, E.; Maestro, M. A.; Mateu, N.; Barrio, P. Chem. Eur. J. 2013, 19, 11776-11785; (b) Antico, P.; Capaccio, V.; Mola, A. D.; Massa, A.; Palombia, L. Adv. Synth. Catal. 2012, 354, 1717-1724; (c) Sović, I.; Stilinović, V.; Kaitner, B.; Kraljević Pavelić, S.; Bujak, M.; Čuljak, 
K.; Novak, P.; Karminski-Zamola, G. J. Mol. Struct. 2011, 1006, 259-265; (d) Williams, F. J.; R. Jarvo, E. R. Angew. Chem. Int. Ed. 2011, 50, 4459-4462; (e) Nieto, S.; Sayago, F. J.; Laborda, P.; Soler, T.; Cativiela, C.; Urriolabeitia, E. P. Tetrahedron 2011, 67, 4185-4191; (f) Takizawa, S.; Inoue, N.; Hirata, S.; Sasai, H. Angew. Chem. Int. Ed. 2010, 49, 9725-9729; (g) Enders, D.; Narine, A. A.; Toulgoat, F.; Bisschops, T. Angew. Chem. Int. Ed. 2008, 47, 5661-5665; (h) Yao, T.; Larock, R. C. J. Org. Chem. 2005, 70, 1432-1437; (i) Mancilla, T.; Carrillo, L.; Zamudio-Rivera, L. S.; Beltrán, H. I., Farfán, N. Org. Prep. Proc. Int. 2001, 33, 341-349; (j) Allin, S. M.; Northfield, C. J.; Page, M. I.; Slawin, A. M. Z. Tetrahedron Lett. 1999, 40, 143-146.

19. Gomes, P.; Araujo, M. J.; Rodrigues, M.; Vale, N.; Azevedo, Z.; Iley, J.; Chambel, P.; Moraisd, J.; Moreira, R. Tetrahedron 2004, 60, 5551-5562.

20. Reyes-González, M. A.; Zamudio-Medina, A.; Ordóñez, M. Tetrahedron Lett. 2012, 53, 5756-5758.

21. Shi, L. Y.; Hu, L.; Wang, J.; Cao, X.; Gu, H. Org. Lett. 2012, 14, 1876-1879.

22. You, H.; Chen, F.; Lei, M.; Hu, L. Tetrahedron Lett. 2013, 54, 2972-2975.

23. Kachkovskyi, G. O.; Kolodiazhnyi, O. I. Phosphorus Sulfur 2009, 184, 890-907.

24. Ordóñez, M.; Tibhe, G. D.; Zamudio-Medina, A.; Viveros-Ceballos, J. L. Synthesis 2012, 44, 569-574.

25. Viveros-Ceballos, J. L.; Cativiela, C.; Ordóñez, M. Tetrahedron: Asymmetry 2011, 22, 1479-1484.

26. Muddala, N. P.; Nammalwar, B.; Bunce, R. A. RSC Adv. 2015, 5, 28389-28393.

27. Adib, M.; Soheilizad, M.; Zhu, L. G.; Wu, J. Synlett 2015, 26, 177-182; Adib, M.; Bayanati, M.; Soheilizad, M.; Janatian Ghazvini, H.; Tajbakhsh, M.; Amanlou, M. Synlett 2014, 25, 2918-2922. Adib, M.; Sheikhi, E.; Haghshenas, P.; RajaiDaryasarei, S.; Bijanzadeh, H. R. Zhu, L. G. Tetrahedron Lett. 2014, 55, 49834986; Adib, M.; Sheikhi, E.; Rezaei, N.; Bijanzadeh, H. R.; Mirzaei, P. Synlett 2014, 25, 1331-1334; Adib, M.; Sheikhi, E.; Bagheri, M.; Bijanzadeh, H. R.; Amanlou, M. Tetrahedron 2012, 68, 3237-3242; Adib, M.; Sheikhi, E.; Bijanzadeh, H. R.; Zhu, L. G. Tetrahedron 2012, 68, 3377-3383.

28. In order to optimize the conditions, the reaction between 2-formylbenzoic acid (1, $\mathrm{X}=\mathrm{H})$, benzylamine $(\mathbf{2}, \mathrm{R}=\mathrm{Bn})$ and trimethyl phosphite $\left(\mathbf{3}, \mathrm{R}^{\prime}=\mathrm{Me}\right)$ was selected as a model reaction for which the molar ratio of the three reactants, reaction temperature, reaction time and effect of solvents were optimized. By 
varying all the parameters, the highest yield was obtained with 1:1:1.1 molar ratio of the three reactants at $25{ }^{\circ} \mathrm{C}$ after 40 min under solvent-free conditions, under which $\mathbf{4 a}$ was obtained in $98 \%$ yield.

29. General procedure for the preparation of $N$-substituted isoindolin-1-one-3phosphonates 4a-p, exemplified with 4a: A mixture of 2-formylbenzoic acid $(0.150 \mathrm{~g}, 1.0 \mathrm{mmol})$, benzylamine $(0.107 \mathrm{~g}, 1.0 \mathrm{mmol})$, and trimethyl phosphite $(0.136 \mathrm{~g}, 1.1 \mathrm{mmol})$ was stirred at ambient temperature for $40 \mathrm{~min}$. After reaction completion (TLC), $n$-hexane/EtOAc $(3: 1,2 \mathrm{~mL})$ was added to the mixture and stirred for $5 \mathrm{~min}$. Next, the mixture was filtered and washed with the same solvent mixture $(1 \mathrm{~mL})$ to give $\mathbf{4 a}$ as a white solid. 
An efficient, three-component synthesis of isoindolin-1-one-3phosphonates under mild and solvent-free conditions

Mehdi Adib, ${ }^{\mathrm{a}, *}$ Ehsan Sheikhi, ${ }^{\mathrm{a}, *}$ Rozita Yazzaf, ${ }^{\mathrm{a}}$ Hamid Reza Bijanzadeh, ${ }^{\mathrm{b}}$ Peiman Mirzaei ${ }^{\mathrm{c}}$

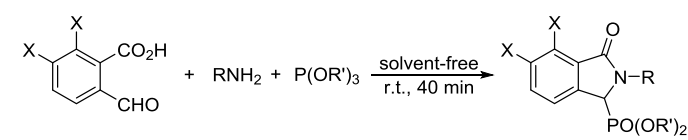

$$
\mathrm{X}=\mathrm{H}, \mathrm{OMe}
$$

$\mathrm{R}=\mathrm{C}_{6} \mathrm{H}_{5} \mathrm{CH}_{2}, 2-\mathrm{ClC}_{6} \mathrm{H}_{4} \mathrm{CH}_{2}$

(R)- $\mathrm{C}_{6} \mathrm{H}_{5} \mathrm{CHCH}_{3},(\mathrm{~S})-\mathrm{C}_{6} \mathrm{H}_{5} \mathrm{CHCH}_{3}$

$\mathrm{R}^{\prime}=\mathrm{Me}, \mathrm{Et}$ 